\title{
Effects of Noise Sensitivity, Noise Exposure, and Affluent Status on Aircraft Noise Annoyance
}

\author{
Veng Kheang Phun', Terumitsu Hirata², Tetsuo Yai ${ }^{3}$ \\ ${ }^{1}$ Institute for Transport Policy Studies, Tokyo, Japan \\ ${ }^{2}$ Department of Urban and Civil Engineering, Ibaraki University, Ibaraki, Japan \\ ${ }^{3}$ Built Environment Department, Tokyo Institute of Technology, Yokohama, Japan \\ Email: kheang@jterc.or.jp, hirata-t@mx.ibaraki.ac.jp, tyai@enveng.titech.ac.jp
}

Received 31 July 2015; accepted 4 September 2015; published 7 September 2015

Copyright (C) 2015 by authors and Scientific Research Publishing Inc.

This work is licensed under the Creative Commons Attribution International License (CC BY). http://creativecommons.org/licenses/by/4.0/

\section{(c) (i) Open Access}

\section{Abstract}

Subjective discomfort of airport community is often assessed as reported noise annoyance in relation to noise exposure level and noise sensitivity. In addition, it has been mentioned that higher affluent people appear to have higher contention to aircraft noise, but there is little literature explicitly supporting that. This paper investigates the relationships among aircraft noise exposure level, noise sensitivity, affluence status, aircraft noise annoyance, and annoyance by other noise sources (e.g., road traffic and neighbor noise). A structural equation model is developed and estimated using data collected from residents, aged between 18 and 77 years old, living near Manila airport in the Philippines $(N=321)$. Results show that noise sensitivity, noise exposure level, and affluent status have positive effects on aircraft noise annoyance, suggesting that higher affluent people are substantially more annoyed by the aircraft noise than lower affluent people. The results also indicate that the annoyance by other noise sources is significantly influenced by noise sensitivity $(p<0.01)$, but not by the affluent status. This implies that people with higher affluent status consider more about the noise generated from aircraft than the noise from other sources. Following an airport development plan, the aviation authorities should also consider the affluent status of nearby communities in order to formulate a better aircraft noise management near that airport.

\section{Keywords}

Affluent Status, Aircraft Noise, Noise Annoyance, Noise Sensitivity, Structural Equation Modeling 


\section{Introduction}

People often use their own definitions and construct their own evaluative contexts in response to the effects of aircraft noise [1]. Individual differences in the perception of aircraft noise could be the cause of noise complaints, opposing to the airport development. Several studies examine the direct relationship between noise exposure levels and annoyance to describe the effects of aircraft noise on people [2]. However, the perceived annoyance itself has been found to be affected by other factors, including background noise [3], frequency of overhead flights [4], time of day [5], and noise sensitivity [6].

Subjective annoyance is also affected by individual consideration about possible noise effects on health. People may promptly react to changes in noise exposure levels if they anticipate adverse health effects [7] [8]. In addition, noise annoyance is shaped by individual positions on aircraft noise and is strongly associated with the policy discourse. Ref. [1] found, based on a discourse resonance theory, that individuals developed their evaluative frames on aircraft noise in relation to the (dominant) policy discourse. While some people may contemplate more on the economic growth rather than opposing the airport development plan, for instance, others may be dissonant with the plan due to distrust in the government to effectively reduce the effects of aircraft noise on nearby communities. The individual position on aircraft noise was investigated using two influential factors: noise exposure and noise sensitivity. Noise sensitivity is defined as personality trait that describes individual attitudes towards the effects of environmental noises [9]. When exposed to a given noise level, certain individuals report high annoyance while some others remain calm. This shows that noise sensitivity is a major predictor of noise annoyance, as has been demonstrated in both the field survey and laboratory experiment [10] [11]. When noise exposure is controlled for, noise sensitivity plays an important role in determining the difference in noise tolerance across individuals.

Further, it is claimed that less affluent people are likely to be more tolerant of aircraft noise or feel unable to express their noise concerns [12]. Such noise tolerance would increase further if local residents benefited from the continued growth of the airport through job opportunities or business improvement. Although affluent status of airport nearby residents is claimed to have effects on noise perception, to the best of our knowledge, there is little study conducted to explicitly supporting that.

This study explores the casual relationship among aircraft noise annoyance, noise exposure level, noise sensitivity, affluent status, and annoyance by other noise sources. We develop a structural equation model (SEM) to investigate the casual relationship among the interested variables, using data collected from an interview survey with residents living near Manila Airport in the Philippines. The outcomes of this study add the understanding of individual perception towards the aircraft noise effects near an airport; specifically the effect of affluent status of airport nearby communities on their annoyance is empirically analyzed.

\section{Methodology}

\subsection{Study Area}

The targeted subjects were those residents living near the Ninoy Aquino International Airport (NAIA), approximately seven kilometers south of Manila in the Philippines. At first, several areas were considered. The local authorities, however, only granted us permission to conduct the survey in five locations, Figure 1. NAIA, the main international gateway for passengers and also the hub for all Philippines airlines, was selected as the study area because it has reached its maximum capacity, and a planning process is underway to accommodate its growing air traffic volume.

There were 62 commercial airline fleets operated at NAIA and approximately 18 million passengers were transported in 2008. NAIA posted 6.46\% increase in aircraft movements for the year 2010 [13]. In 2012, NAIA handled a total of 37 airlines for both international and domestic flights, yielding an increase in the commercial airline fleets to 119 with about 30 million passengers [14]. The increase in air transport service has affected the runway capacity. The runways of NAIA were reported to possibly accommodate an average of 36 takeoffs/ landings per hour, but the actual scheduled flights went up to 50 movements per hour. Consequently, traffic in NAIA reaches its maximum capacity during peak hours, resulting flight delays and cancellations [13] [14].

According to the Civil Aviation Authority of the Philippines (CAAP), NAIA's secondary runway (RWY13/ 31) has just opened to full operational aircraft services in order to decongest air traffic at the country's premier airport. RWY13/31 has been upgraded to allow instrument operations. This runway is in operation only on a 


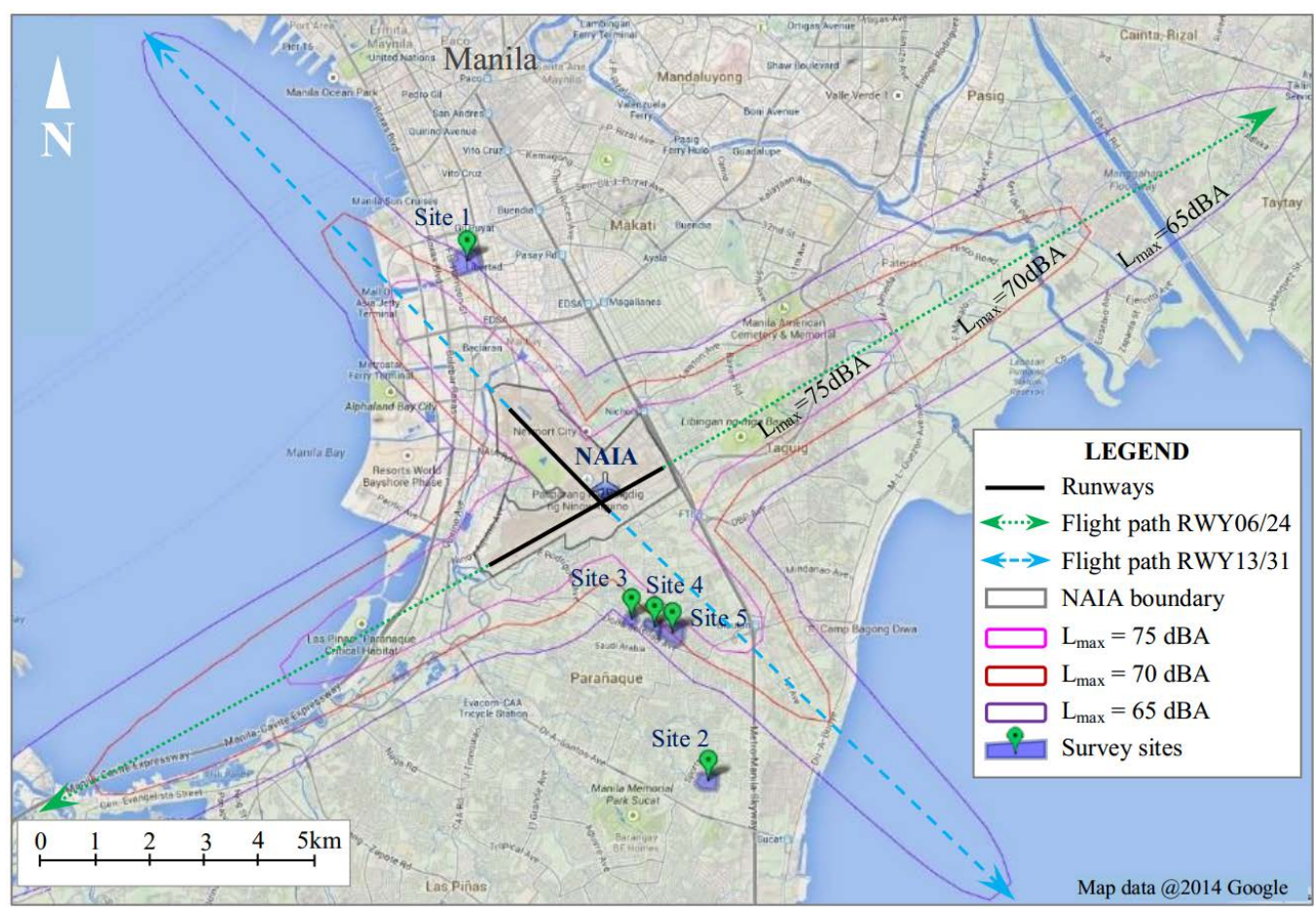

Figure 1. Study area and estimated noise contour maps of NAIA.

limited basis; for example, only southbound departures are allowed from this runway due to security reasons, while the operations of the northbound takeoffs were prohibited due to the possibility of aircraft incursions towards the Malacañang airspace (Danilo Atienza Air Base). To accommodate the ever-increasing air traffic volume, the CAAP resolved the security issues by plotting a new take-off pattern that would prevent the intrusion of aircrafts over the presidential air space. The new take-off pattern currently allows up to 550 flights daily, on average, with about 450 flights using the main runway RWY06/24 and the remaining flights using RWY13/ 31, only if the wind conditions are favorable. Based on an estimate in [15], more than 200,000 people living within a six-kilometer radius from RWY06/24 were affected by a day night average noise level (DNL) of $65.0 \mathrm{dBA}$ or above. This number is expected to increase following the new operation of the secondary runway. Targeted subjects were mainly those living along the flight paths using the secondary runway.

\subsection{Aircraft Noise}

The official noise contour map at NAIA has not yet been made available to detail the recent operations of the secondary runway. For our analysis, we used the Integrated Noise Modeling package (INM 7.0) to generate the noise contour maps; so that, the (outdoor) noise exposure levels near the airport can be assessed. Due to the cross wind, the landing/takeoff operations can be made for all directions of both runways. Because the noise exposure level from a departure of an aircraft is relatively higher than the noise from a landing operation, we estimated the noise generated from a single departure operation for all departure directions. The operating aircraft types were chosen based on the actual evening flights: B777-300 and A320 for both departures from ends of runway RWY06/24 and RWY13/31, respectively. In this study, a maximum sound level $\left(L_{\max }\right)$ measured in A-weighted decibel ( $\mathrm{dBA}$ ) was selected as the acoustical unit. Noise was measured in $\mathrm{dBA}$ in order to account for the relative loudness perceived by human ear. $L_{\max }$ is the measurement of a single noise event and it is used here as a proxy variable representing the cumulative noise metric (i.e., DNL) at NAIA. The estimated noise contour maps were illustrated in Figure 1. The average noise exposure levels were $L_{\max }=67.4 \mathrm{dBA}$ at site 1 , $L_{\max }=52.6 \mathrm{dBA}$ at site $2, L_{\max }=65.5 \mathrm{dBA}$ at site $3, L_{\max }=67.8 \mathrm{dBA}$ at site 4 , and $L_{\max }=68.6 \mathrm{dBA}$ at site 5 . Because the size of the survey sites were small and address of interviewed residents was not recorded, each participant was assumed to be affected by the site' average noise exposure level. This resulted in $\pm 5.0 \mathrm{dBA}$ variation in noise exposure levels measured within the survey sites. 


\subsection{Interview Survey}

A face-to-face interview survey was carried out by canvassing door-to-door in the permitted survey sites near NAIA. Three experienced interviewers, who were trained to fully understand and administer the questionnaire, visited approximately 500 houses from May 27 to June 3, 2013. The effective sample size was obtained from 321 volunteer participants, aged between 18 and 77 years old. Each participant received a monetary incentive of 100 Philippine Pesos (PhP, $100 \mathrm{PhP}=3.32$ US \$, as of June 2013) for their time participation in the survey. The questionnaire was first written in English and later translated into Tagalog version.

The questions were verbally back-translated into English in a pilot test, to ensure the consistency between the Tagalog and English versions. Although many of the Filipinos who were questioned could actually understand English, the interview was conducted in Tagalog in order to assist local residents in clearly understand the contents of the questionnaire. The questionnaire comprised of six sections. Section 1 and 5 inquired about general noise perceptions that occurred on a daily basis. The questions were designed based on previous aircraft noise studies and according to the real situations at NAIA. Twenty questionnaire items were designed using a 7-point scale (1: unlikely, 4: neither, and 7: likely) because it is easy for participants to decide their judgments [16]. Section 2-4 inquired about individual noise tolerance levels (i.e., the tolerable flyovers per hour) under a hypothetical airport. Section 6 inquired about personal information including age and income. This study only uses the information on the general noise awareness (e.g., annoyance by road, rail, and air traffic) and general noise sensitivity from Section 1 and 5, and the personal information from Section 6. After the information screening process, the collected data are valid for further analyses.

\subsection{Participant Characteristics}

The characteristics of participants are summarized in Table 1. They had an average age of 38 years old. Majority of them was female (63.9\%), married (65.4\%), and living in their own house (73.8\%). For those living in a rented house (26.2\%), the average rental free was $3240 \mathrm{PhP}$. 31.0\% of the participants were staff of a company/government, having both part time and fulltime job, and $11.4 \%$ had own business. In average, except for

Table 1. The characteristics of participants $(N=321)$.

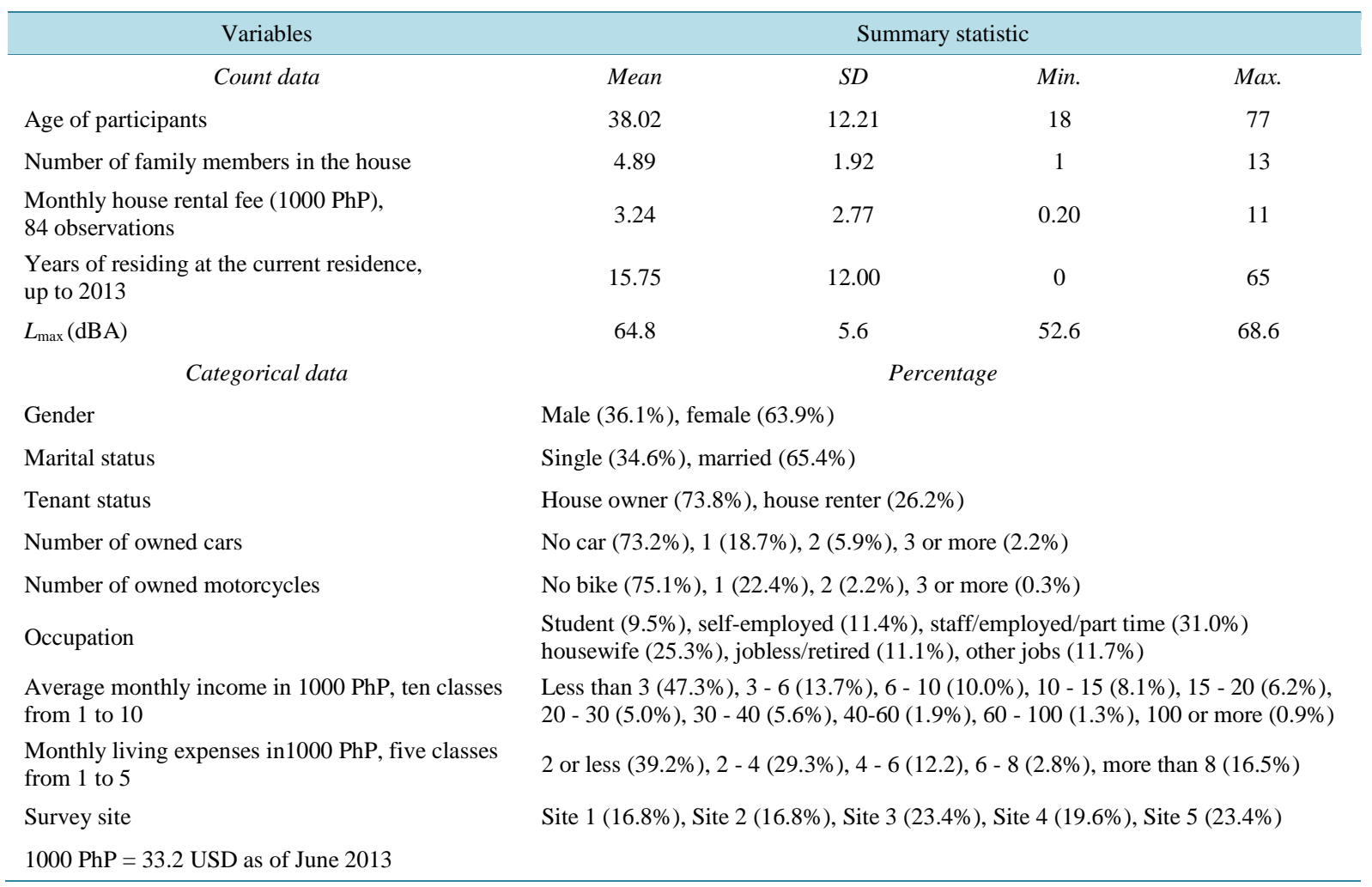


house and tuition fee, the participants spent approximately $4450 \mathrm{PhP}$ for their monthly living including transportation fee, foods, and health. However, more than haft (61.0\%) could earn less than $6000 \mathrm{PhP}$ per month. This because $25.3 \%$ of the participants were housewives, and their living expenses may mainly be based on the husbands' income. While majority did not own a vehicle (73.2\% had no car and $75.1 \%$ had no motorcycle), their common modes of transportation (88.8\%) were public bus and paratransit (i.e., Jeepney, taxi, tri-cycle). In 2013, the average period of residence was about 16 years. Based on our estimation, interviewed residents at their current house were exposed to an average aircraft noise of $L_{\max }=64.8 \mathrm{dBA}$.

\section{Model and Hypotheses}

\subsection{Measurement Model}

For the measurement model, four latent variables (i.e., Aircraft noise annoyance, Annoyance by other noise sources, Noise sensitivity, and Affluent status) are defined to confirm the casual relationship among these variables, see Figure 2. Each latent variable is operationalized using at least three questionnaire items, which would results in less biased estimates between the structural variables in the model. The model is specified by assuming that each set of items indicates its corresponding latent construct. Each item represents a subjective question, evaluated based on the 7-point scale (1: unlikely, 4: neither, and 7: likely). Table 2 shows the descriptive statistics of these questionnaire items for each latent variable.

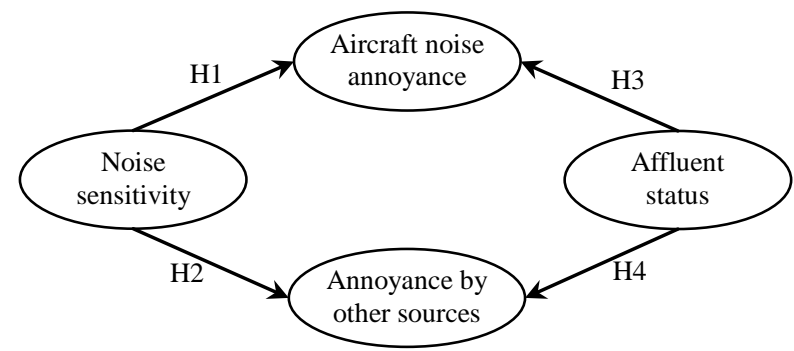

Figure 2. Conceptual SEM model and stated hypotheses.

Table 2. Descriptive statistics of the subjective variables of the model.

\begin{tabular}{|c|c|c|c|c|c|}
\hline Latent variables and corresponding indicators & Effect & Mean & $S D$ & Min. & Max. \\
\hline \multicolumn{6}{|l|}{ Aircraft noise annoyance } \\
\hline Aircraft noise is more annoyed than other noise & $(+)$ & 2.91 & 1.87 & 1 & 7 \\
\hline Annoyed by aircraft noise & $(+)$ & 2.93 & 1.85 & 1 & 7 \\
\hline Aware of problems causing by aircraft noise & $(+)$ & 2.94 & 1.82 & 1 & 7 \\
\hline Bearable several times with moderate aircraft noise & $(-)$ & 4.86 & 1.96 & 1 & 7 \\
\hline Care about aircraft noise when hearing indoor & $(+)$ & 3.67 & 2.05 & 1 & 7 \\
\hline Importance to have airport in the city & $(-)$ & 5.01 & 2.17 & 1 & 7 \\
\hline \multicolumn{6}{|l|}{ Annoyance by other sources } \\
\hline Annoyed by neighbor noise & $(+)$ & 3.70 & 2.38 & 1 & 7 \\
\hline Annoyed by rail traffic noise & $(+)$ & 1.99 & 1.67 & 1 & 7 \\
\hline Annoyed by road traffic noise & $(+)$ & 3.36 & 2.05 & 1 & 7 \\
\hline \multicolumn{6}{|l|}{ Noise sensitivity } \\
\hline Being easily awaken by noise & $(+)$ & 4.51 & 2.35 & 1 & 7 \\
\hline Good at concentrating & $(-)$ & 4.78 & 1.94 & 1 & 7 \\
\hline Sensitive to noise & $(+)$ & 4.01 & 2.23 & 1 & 7 \\
\hline
\end{tabular}


The "noise annoyance" construct is subjective in nature. To correct this construct for structural and random measurement errors, it is measured indirectly by six items related to the following questions: 1) Do you think aircraft noise is more annoyed than noise from other noise sources? 2) How likely does aircraft noise often annoy you? 3) How much do you know about the problems causing by aircraft noise? 4) Do you think you can endure with aircraft sound which is moderately loud several times per hour? 5) Do you care about aircraft noise when you hear it inside your house? And 6) Do you think it is important to have an airport in this area? Based on the average scores, it showed that participants highly acknowledged the important role of airport in their living area (5.01) while they appeared to get used to the moderately loud aircraft noise (4.86). The aircraft noise annoyance is expected to be positively influenced by items $1,2,3, \& 5$, and negatively influenced by items 4 \& 6 .

The "annoyance by other noise sources" construct is indirectly measured by three questionnaire items, relevant to the subjective responses of annoyance by rail traffic, road traffic, and neighbor noise. It was observed that the most annoying source was noise from neighbors, following by the noise from road traffic, and from air traffic. Higher score of each item represents a higher level of annoyance by other noise sources.

Three items were used as indicators for the "noise sensitivity" construct. They are associated with the following general noise sensitivity questions: 1) Are you easily awoken by noise? 2) Are you good at concentrating no matter what is going on around you? And 3) Are you sensitive to noise? The average score (4.01) indicates that participants were moderately noise sensitive people. Noise sensitivity is likely to have higher value for individual who is sensitive to noise (Item 3) and who is easily awoken by noise while sleeping (Item 1), but have lower value for individual who is good at concentrating no matter what is happening around (Item 2).

For the "Affluent status"' construct, indicators are those variables representing the wealthy level of each individual such as the monthly average income and expense, number of own vehicles (car and motorcycle), and occupation. A higher value of each item indicates a higher affluent status of an individual. For instance, individual with higher average income or with more monthly expense is whose wealthy level is higher.

The noise exposure level, as contextual variable, is expected to have a positive effect on aircraft noise annoyance. This refers to the hypothesis that individual would have higher annoyance due to aircraft noise when they are exposed to a higher aircraft noise level [17]. On the other hand, the objective variables included in the model are individual age, marital status as married, rental fee of house, and the period of residing at the current house. The effects of these variables on latent constructs are to be explored.

\subsection{Hypotheses}

There are four hypotheses (H1, H2, H3, and H4) to be tested in the SEM; two related to the effects of "noise sensitivity" and other two related to the effects of "affluent status" on "aircraft noise annoyance" and "annoyance by other noise sources," see Figure 2. Positive effects are expected for the four hypotheses. Individual who is sensitive to surrounding noise are likely to be more annoyed by that noise [6] [18]-[20]. Moreover, individual who have higher affluent status is likely to react stronger to the noise annoyance from various noise sources [12] [21] [22]. This is true because richer people would prefer better environmental amenities including quietness around their living places.

\section{Results}

Figure 3 shows the results of the structural equation modeling that was employed to test the four hypotheses. The model was estimated using the statistical package AMOS 7.0, and its estimated standardized effects are provided in the figure, annexing to each path effect. The model has $\chi^{2}$ value of 645.211 with 197 degrees of freedom (df), which is significant $(p<0.000)$. The ratio between $\chi^{2}$ and $\mathrm{df}$ is computed at 3.275 , which falls between 2 and 5, indicating a reasonable fit [23]. This model has the goodness-of-fit index (GFI) of 0.860 and the adjusted goodness of fit index (AGFI) of 0.820, which are slightly lower than 0.9 [23]. In addition, the root mean square error of approximation (RMSEA) has value of 0.084, a badness-of-fit index, which is slightly higher than 0.080 for a good fit but lower than the upper limit of 0.10 . It seems the overall goodness-of-fit of the model is adequate for us to investigate the casual relationship among the interested variables.

The numbers at the tails of arrows pointed to latent variables represents the percentages of explained variance in each endogenous latent construct. Particularly, $R$-square value for the aircraft noise annoyance is 0.25 , indicating that $25 \%$ of variance is explained; this is reasonably high comparing to previous studies (e.g., [6] [17] [24]). 


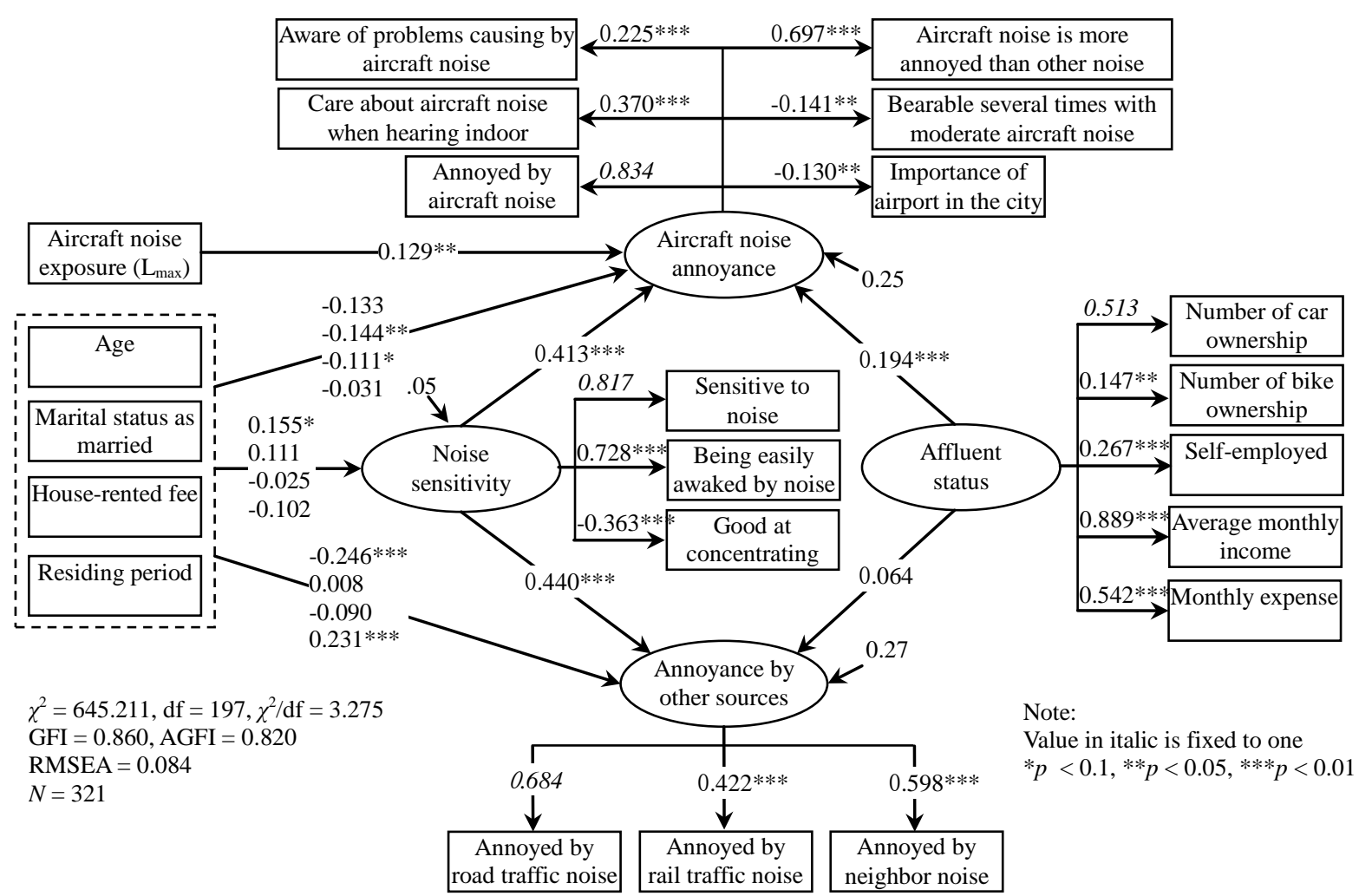

Figure 3. Structural equation model and its estimate results with standardized effects.

\subsection{Effects of Noise Sensitivity}

Results show that the noise sensitivity construct has a positively significant effect on aircraft noise annoyance (H1, $p<0.01$ ), consistent with the literature [20]. It is shown that noise sensitivity was not related to noise exposure level, but rather included as an effect modifier in the noise-annoyance relation. Noise sensitivity is regarded as a major non-acoustical factor in determining individual reaction to noise; especially, it is a major antecedent of aircraft noise annoyance, accounting for $10 \%-26 \%$ of the explained variance in reaction responses [19]. Noise sensitivity seems to influence annoyance irrespective of aircraft noise exposure level [6]. To this end, by reducing high noise exposure level does not necessarily mean reducing noise impacts for highly noise sensitive people, who simply get annoyed at low noise level.

Positive effect of noise sensitivity on the annoyance by other noise sources is also significantly confirmed (H2, $p<0.01$ ). This finding is consistent with previous studies (e.g., [25]). Considering across noise sensitivity groups, it was found through a laboratory experiment that annoyance increased with sensitivity to outdoor noise, including road and rail noise [18]. According to [26], approximately one out of five people are highly sensitive to moderately loud noise. Any planning that involves with environmental noise problems should consider the noise sensitivity people because noise sensitivity is a major cause of annoyance and other health related problems [18].

Further, noise sensitivity has previously been found to positively be influenced by age [6]. A similar influence is observed in this study; the effect of age on noise sensitivity is statistically significant at $10 \%$ confidential level. Other objective variables have insignificant effects on noise sensitivity. The sometime weak relationship between objective characteristics and latent constructs led to the belief that objective variables alone are not sufficient as determinants of a latent construct [17]. The percentage of explained variance is small $(R$-square $=0.05)$, however, the indicators of noise sensitivity construct are highly significant.

\subsection{Effects of Affluent Status}

The results show that the affluent status has a highly significant effect on aircraft noise annoyance (H3, $p<0.01)$. 
The positive sign indicates that individual with higher affluent status appeared to have higher annoyance by aircraft noise. This finding is supported by [22] which found that people living in the area of greatest affluence have a significantly greater proportion of high annoyance due to aircraft noise. On the other hand, the noise complaint is partially linked to the affluent status of airport-nearby communities [12]. The potential to act as constraints to an airport development vary considerably with the social and economic needs. Less affluent people appear to be more tolerable with aircraft noise or weak to express their opposition to noise. Tolerance of aircraft noise for less affluent people would further increase if they receive benefits from the airport development. However, high socioeconomic people have higher awareness of noise [27]. In contrast to low socioeconomic people, they feel easier to avoid noise exposure (e.g., by relocation or having soundproofing installed in their houses).

The affluent status had insignificant effect on annoyance by other noise sources $(\mathrm{H} 4, p=0.449)$. This implies that participants were not annoyed by other noise sources (rail, road, and neighbor noise). Although high affluent people near NAIA were not critically affected by other noise sources, they were indeed affected by the aircraft noise. The relationship between the affluent status and subjective annoyance by other noise sources (not aircraft noise) might not be alike among people in developing and developed countries. In particular, there is a case that annoyance due to road traffic noise was found to be influenced by affluent and education status in France, but this was supported by the fact that a number of people with high affluent and educated neighborhoods were exposed to very high traffic noise in at least part of the nearby areas [27].

It should be noted that the effect of affluent status on noise sensitivity was found to be insignificant and the corresponding path was removed from the model. This indicates that higher sensitivity to noise were not among wealthier participants. A conflict result was found for affluent communities around a UK regional airport [22].

\subsection{Effects of Other Variables}

Aircraft noise exposure has a positively significant effect on aircraft noise annoyance $(p<0.05)$. This finding is consistent with previous research which has continuously reported that the subjective noise annoyance is closely linked to the noise exposure level [1]. Noise exposure level is often reported together with the corresponding subjective impression to describe the impacts of aircraft noise on human [2] [7]. This is one of the criteria to assess the impacts of long term noise exposure [28]. Noise exposure is also used as potential variable to assess the property values affected by aircraft noise in the vicinity of airport [29]. In sum, noise exposure level serves as a potential variable for studies on the impacts of aircraft noise on airport nearby properties and lives.

Results also show some significant effects of the objective variables on noise annoyance. For instance, the individual age has positive effect on noise sensitivity and negative effect on annoyance by other noise sources. Although older participant appeared to have higher noise sensitivity, they are less likely to be annoyed by ground transportation and neighbor noise, and they did care about the aircraft noise. Further, results suggest that participant who were residing longer period at the current house appeared to be more annoyed by the surrounding noise. Participant with longer residing period might have observed the increase in noise exposure level around the house due to, for example, increase in road traffic volume. By seeing so, the participant may have concerned over the surrounding noise.

\section{Conclusions}

This study explored the casual relationship among aircraft noise exposure, noise sensitivity, affluent status, and annoyance by aircraft noise and other noise sources. We paid special focus on the effects of noise sensitivity and affluent status on aircraft noise annoyance. The causal relationship was investigated under a structural equation modeling. The best selected model was estimated using data collected from interview survey with residents living near NAIA in the Philippines. The results showed positively significant effects of noise sensitivity on annoyance due to aircraft noise and other noise sources (road, rail, and neighbor noise), consistent with previous studies. In addition, it was found that the affluent status had positively significant effect on the annoyance due to aircraft noise (i.e., not other noise sources), empirically confirming the claims by the literatures. Moreover, the effect of noise sensitivity was about twice, comparing to the effect of affluent status on aircraft noise annoyance. This indicates that primary provision of aircraft noise countermeasures for highly noise sensitive people and then affluent residents would help the aviation authorities to lessen the noise contention by the airport-nearby communities and to better manage the aircraft noise near airport. 
The problem caused by aircraft noise will remain the main obstacle to airport growth following increased demand for air transport services. In addition to technological improvement and the available noise mitigation procedures [30], on the other perspectives, the impacts of aircraft noise can possibly be minimized by addressing the differences in individual noise perception (e.g., noise sensitive person) and individual characteristics (e.g., affluent status, education level). Further research is required to profoundly investigate the effects of differences in individual attitude and social status towards the environmental noise-so that the appropriate noise countermeasures could be suggested as number of flights seems to increase worldwide.

\section{Acknowledgements}

The authors would like to thank Dr. Karl Vergel, Dr. Ernesto Abaya, and other members of UP-NCTS for their kind helps with data collection. Phun V. K. thanks AUN/Seed-Net JICA for scholarship support.

\section{References}

[1] Kroesen, M., Molin, E.J.E., Miedema, H.M.E., Vos, H., Janssen, S.A. and Van Wee, B. (2011) Policy, Personal Dispositions and the Evaluation of Aircraft Noise. Journal of Environmental Psychology, 31, 147-157. http://dx.doi.org/10.1016/j.jenvp.2010.09.004

[2] Brink, M., Wirth, K.E. and Schierz, C. (2008) Annoyance Responses to Stable and Changing Aircraft Noise Exposure. The Journal of the Acoustical Society of America, 124, 2930-2941. http://dx.doi.org/10.1121/1.2977680

[3] Lim, C., Kim, J., Hong, J. and Lee, S. (2008) Effect of Background Noise Levels on Community Annoyance from Aircraft Noise. The Journal of the Acoustical Society of America, 123, 766-771. http://dx.doi.org/10.1121/1.2821985

[4] Kuwano, S. and Namba, S. (1996) Evaluation of Aircraft Noise: Effects of Number of Flyovers. Environmental International, 22, 131-144. http://dx.doi.org/10.1016/0160-4120(95)00110-7

[5] Carlson, F., Lampi, E. and Martinsson, P. (2004) The Marginal Values of Noise Disturbance from Air Traffic: Does the Time of Day Matter? Transportation Research Part D, 9, 373-385. http://dx.doi.org/10.1016/j.trd.2004.07.002

[6] Van Kamp, I., Jo, R.F.S., Hatfield, J., Haines, M., Stellato, R.K. and Standfeld, S.A. (2004) The Role of Noise Sensitivity in the Noise-Response Relation: A Comparison of Three International Airport Studies. The Journal of the Acoustical Society of America, 116, 3471-3479. http://dx.doi.org/10.1121/1.1810291

[7] Babish, W., Houthuijs, D., Pershagen, G., Cadum, E., Katsouyanni, K., Velonakis, M., et al., HYENA Consortium (2009) Annoyance Due to Aircraft Noise Has Increased over the Years-Results of the HYENA Study. Environmental International, 35, 1169-1176. http://dx.doi.org/10.1016/j.envint.2009.07.012

[8] Berglund, B., Lindvall, T. and Nordin, S. (1990) Adverse Effects of Aircraft Noise. Environmental International, 16, 315-338. http://dx.doi.org/10.1016/0160-4120(90)90002-N

[9] Zimmer, K. and Ellermeier, W. (1999) Psychometric Properties of Four Measures of Noise Sensitivity: A Comparison. Journal of Environmental Psychology, 19, 295-302. http://dx.doi.org/10.1006/jevp.1999.0133

[10] Standfeld, S.A. (1992) Noise, Noise Sensitivity and Psychiatric-Disorder-Epidemiologic and Psychophysiological Studies. Psychiatric Medications, 22, 1-44.

[11] Ellermeier, W., Eigenstetter, M. and Zimmer, K. (2000) Psychoacoustic Correlates of Individual Noise Sensitivity. The Journal of the Acoustical Society of America, 109, 1464-1473. http://dx.doi.org/10.1121/1.1350402

[12] Upham, P., Maughan, J., Raper, D. and Thomas, C. (2003) Towards Sustainable Aviation. Earthscan Publication, New York, 97-111.

[13] CAAP, Civil Aviation Authority of the Philippines (2011) PBN Implementation Plan. Version 2.0, Airspace \& Flight Procedure Design Division-Air Traffic Service. http://www.icao.int/safety/pbn/PBNStatePlans/Philippines\%20PBN\%20Implementation\%20Plan\%202011.pdf

[14] Fabian, F.N.G., Jung, Y.G.K., Montealto, K.A.L., Yu, A.C. and Gueta, G.P. (2013) The Impact of the Emergence of Low-Cost Carriers and Budget Flights. Proceedings of the 10th Eastern Asia Society for Transport Studies, Taipei, 9-12 September 2013.

[15] Abaya, E.B., Sigua, R.G. and Vergel, K.N. (2006) The Impacts of Aircraft Noise on Communities in the Vicinity of the Ninoy Aquino International Airport. Philippine Engineering Journal, 27, 71-84.

[16] Miller, G.A. (1956) The Magical Number Seven, Plus or Minus Two: Some Limits on Our Capacity of Processing Information. Psychological Review, 101, 343-352. http://dx.doi.org/10.1037/h0043158

[17] Kroesen, M., Molin, E.J.E., Miedema, H.M.E., Vos, H., Janssen, S.A. and Van Wee, B. (2010) Estimation of the Effects of Aircraft Noise on Residential Satisfaction. Transportation Research Part D, 15, 144-153.

http://dx.doi.org/10.1016/j.trd.2009.12.005 
[18] Fyhri, A. and Klæboe, R. (2009) Road Traffic Noise, Sensitivity, Annoyance and Self-Reported Health-A Structural Equation Model Exercise. Environmental International, 35, 91-97. http://dx.doi.org/10.1016/j.envint.2008.08.006

[19] Ryu, J.K.J. and Jeon, J.Y. (2011) Influence of Noise Sensitivity on Annoyance of Indoor and Outdoor Noises in Residential Buildings. Applied Acoustics, 72, 336-340. http://dx.doi.org/10.1016/j.apacoust.2010.12.005

[20] Taylor, S.M. (1984) A Path Model of Aircraft Noise Annoyance. Journal of Sound and Vibration, 96, 243-260. http://dx.doi.org/10.1016/0022-460X(84)90582-0

[21] Halpern, D. (2013) Mental Health and the Built Environment: More than Bricks and Mortar? 2nd Edition, Routledge, New York.

[22] Whitfield, A. (2003) Assessment of Noise Annoyance in Three Distinct Communities Living in Close Proximity to a UK Regional Airport. International Journal of Environmental Health Research, 13, 361-372. http://dx.doi.org/10.1080/0960312031000122451

[23] Hooper, D., Coughlan, J. and Mullen, M.R. (2008) Structural Equation Modelling: Guideline for Determining Model Fit. The Electronic Journal of Business Research Methods, 6, 53-60.

[24] Kroesen, M., Molin, E.J.E. and Van Wee, B. (2008) Testing a Theory of Aircraft Noise Annoyance: A Structural Equation Analysis. The Journal of the Acoustical Society of America, 123, 4250-4260. http://dx.doi.org/10.1121/1.2916589

[25] Langdon, F.L. (1976) Psychometric Properties of Four Measure of Noise Sensitivity: A Comparison. Journal of Sound and Vibration, 47, 265-282. http://dx.doi.org/10.1016/0022-460X(76)90721-5

[26] Luz, G.A. (2005) Noise Sensitivity Rating of Individuals. Journal of Sound and Vibration, August, 14-17. http://www.sandv.com/downloads/0508luz.pdf

[27] Méline, J., Van Hulst, A., Thomas, F., Karusisi N. and Chaix, B. (2013) Transportation Noise and Annoyance Related to Road Traffic in French RECORD Study. International Journal of Health Geographics, 12, 44. http://dx.doi.org/10.1186/1476-072x-12-44

[28] Clark, C., Head., J. and Stansfeld, S.A. (2013) Longitudinal Effects of Aircraft Noise Exposure on Children's Health and Cognition: A Six-Year Follow-Up of the UK RANCH Cohort. Journal of Environmental Psychology, 35, 1-9. http://dx.doi.org/10.1016/j.jenvp.2013.03.002

[29] Nelson, J.P. (2004) Meta-Analysis of Airport Noise and Hedonic Property Values: Problems and Prospects. Journal of Transport Economics and Policy, 38, 1-27.

[30] Girvin, R. (2009) Aircraft Noise-Abatement and Mitigation Strategies. Journal of Air Transport Management, 15, 1422. http://dx.doi.org/10.1016/j.jairtraman.2008.09.012 